\title{
ESCOLARIZAÇÃO E TERRITORIALIDADE NA CIDADE REPUBLICANA: BELO HORIZONTE (1897-1912)
}

DOI: http://dx.doi.org/10.1590/2236-3459/66340

\author{
Maria Cristina Soares Gouvea \\ Universidade Federal de Minas Gerais, Brasil. \\ Karina Nicácio \\ Universidade Federal de Minas Gerais, Brasil.
}

$\cos 80$

\begin{abstract}
Resumo
$\mathrm{O}$ artigo tem como tema as relações entre demandas sociais e políticas estatais de instrução no decorrer da Primeira República. Tendo como cenário a cidade de Belo Horizonte, materialização do projeto republicano de ordenamento urbano, busca-se analisar o acesso à instrução das distintas populações, a partir de sua ocupação do território. Referenciado no diálogo entre história, geografia e urbanismo, focaliza-se a dinâmica entre o investimento em escolarização da população habitante das colônias agrícolas, preponderantemente de imigrantes, e as ações estatais no período entre sua criação, em 1897, e incorporação à zona suburbana em 1912. Verifica-se que a política segregacionista característica da planificação da cidade, em que a ocupação territorial foi definida de acordo com a condição social e étnico-racial das populações, impôs condições desiguais de acesso à escola. Por outro, dada a dinâmica de apropriação dos territórios pelas distintas populações, a mobilização dos habitantes das colônias pela instrução pública fez com que o Estado, ainda que de forma precária, destinasse recursos à escolarização desses grupos sociais.

Palavras-chave: escola, cidade, territorialização, imigração.
\end{abstract}

\section{SCHOOLING AND TERRITORIALISATION ON THE REPUBLIC CITY: BELO HORIZONTE (1897-1912)}

\begin{abstract}
The article focuses on the relationship between schooling demands and state policies during the First Republic. Set in the city of Belo Horizonte, materialization of the republican project of urban planning, it seeks to analyse the access to education of the different populations, considering their occupation of the territory. Using as analytical reference the dialogue between history, geography and urban planning, it focuses on the dynamic between the demands for schooling from the immigrant population inhabitant of agricultural colonies and state actions in the period between its


creation in 1897 and incorporation to the suburban area in 1912. The segregationist policy of territorial occupation, defined according to the social and ethnic-racial condition of the city's population imposed conditions of unequal access to school. Even them, it is possible to identify investment and mobilization from the inhabitants of the colonies in their instruction Key-words: schooling, city, territorialization, immigration.

\section{ESCUELA Y TERRITORIALIZACCIÓN EN LA CUIDAD REPUBLICANA: BELO HORIZONTE (1897-1912)}

\section{Resumen}

El artículo se centra en la relación entre las necesidades sociales y la educación de las políticas del Estado durante la Primera República. Situado en la ciudad de Belo Horizonte, la materialización del proyecto republicano de la planificación urbana, el artículo busca analizar el acceso a la educación de las diferentes poblaciones, desde su ocupación del territorio. Se hace referencia en el diálogo entre la historia, la geografía y la planificación urbana, se centra en la dinámica entre la inversión en la educación de la población local de las colonias agrícolas, principalmente inmigrantes, y las acciones del Estado en el período comprendido entre su creación en 1897, y la incorporación a la zona suburbana 1912. Parece que la característica política segregacionista de la planificación de la ciudad, donde se definió la ocupación territorial de acuerdo con la situación social y étnico-racial de las poblaciones, impuso condiciones desiguales de acceso a la escuela. Por otro lado, dada la dinámica de apropiación de territorios por diferentes poblaciones, la movilización de los habitantes de las colonias por la educación pública ha hecho que lo Estado, aunque precariamente, ha asignado recursos a la educación de estos grupos sociales.

Palabras-clave: escuela, territorializaccion, ciudad, imigraccion.

\section{ÉCOLE ET TERRITOIRE ET LA VILLE REPUBLICAIN: BELO HORIZONTE (1906-1912)}

\section{Résumé}

L'article se concentre sur la relation entre les besoins sociaux et l'éducation des politiques de l'Etat au cours de la Première République. Situé dans la ville de Belo Horizonte, la matérialisation du projet républicain de la planification urbaine, il cherche à analyser l'accès à l'éducation des différentes populations, de leur occupation du territoire. Référencé dans le dialogue entre l'histoire, la géographie et la planification urbaine, il se concentre sur la dynamique entre l'investissement dans l'éducation de la population locale des colonies agricoles, principalement les immigrants et les actions de l'Etat dans la période entre sa création en 1897, et l'incorporation dans la zone suburbaine 1912. il semble que la caractéristique de la politique ségrégationniste de la planification de la ville, où l'occupation territoriale a été définie en fonction de la situation sociale et ethnoraciale des populations, a imposé des conditions inégales d'accès à l'école. D'autre part, étant donné la dynamique d'appropriation de territoires par différentes populations, la mobilisation des habitants des colonies par l'éducation du public a fait l'État, bien que précaire, les ressources destinées à l'éducation de ces groupes sociaux.

Mots-clé: école, territoire, ville, immigrants. 


\section{Introdução}

instauração do regime republicano no Brasil implicou numa radicalização de
estratégias de governo das populações e ordenamento social que emergiram
ao final do Império, diante de uma sociedade de homens livres. Por um lado, com o fim do regime escravocrata, a lei atribuía a todos a condição de sujeitos. Por outro, as condições de exercício da cidadania mostravam-se restritas, entendidas não como direito, mas como conquista do indivíduo, diante de alguns atributos, como do direito de voto, acessível apenas à população masculina letrada, segundo a lei Saraiva de 1881 .

Se a República não inaugurou uma concepção restritiva de cidadania, a partir do regime instauram-se novos dispositivos de governo das distintas populações, principalmente tendo em vista sua identidade nacional e étnico-racial. Tais políticas tomam, não apenas como cenário, mas como espaço de intervenção a cidade. Busca-se atuar na ocupação dos espaços urbanos de forma a garantir que a circulação e moradia fossem definidas por critérios de segmentação e hierarquização.

O acesso à instrução no período configura-se neste cenário complexo de ampliação e, ao mesmo tempo, de restrição de direitos (Carvalho, 2008). Especialmente nos territórios urbanos a demanda por instrução pelas populações conjuga-se à reinvindicação por outros direitos sociais, relacionados ao espaço que ocupam e seu trânsito pela cidade. Condições de mobilidade, habitação, acesso à saúde e instrução se integram na demanda por melhores condições de vida e são objeto de políticas governamentais, quer de atendimento, quer de negação ${ }^{1}$. Tais demandas envolvem uma dimensão espacial e, no caso da escola, sua localização ou ausência expressa as relações entre Estado e populações no acesso à instrução.

Pretende-se explorar a dimensão espacial do processo de escolarização nos primeiros anos do período republicano. Para tal, tomamos como objeto de investigação a cidade de Belo Horizonte, materialização do modelo urbano de intervenção republicana. Se em artigo anterior (Gouvea et al, 2016) contemplamos as relações entre os modelos de organização da escola - grupos escolares e escolas isoladas - e sua localização na cidade, iremos focalizar um grupo social específico: a população das colônias agrícolas da cidade, preponderantemente imigrantes, investigando a demanda por escolas e seu atendimento pelo poder público ${ }^{2}$.

Tendo como fontes relatórios de inspetores, mensagens de presidente do Estado, relatórios de gestão municipal, mapas de matrícula e frequência, jornais da época, cartas e abaixo assinados, mapas cartográficos, além do recurso à historiografia da cidade e sua educação ${ }^{3}$, buscamos apreender a escolarização em uma das Colônias Agrícolas de Belo Horizonte no período entre 1898, data da criação das mesmas, e 1912, quando estas são extintas e incorporadas à zona suburbana da cidade.

Assim, incialmente, se estabelece os referenciais analíticos, ancorados no diálogo com os campos da história, geografia e urbanismo. Posteriormente iremos contempla-los no estudo da constituição de Belo Horizonte e sua ocupação, focalizando as colônias

\footnotetext{
${ }^{1}$ Sobre lutas sociais do período vide, entre outros, o dossiê Gomes (2009).

2 Ambos trabalhos resultam da pesquisa Escolas isoladas e reunidas: demandas sociais e produção da precarização (Belo Horizonte 1906- 1927), que contou com apoio do Cnpq (2012-2016).

3 Especialmente importantes, tanto pelas fontes, quanto pelas análises, foram os excelentes trabalhos de tese de Aguiar (2006) e Rodrigues (2009).

Hist. Educ. (Online) Porto Alegre

v. 21

ก. 51

Jan./abr., 2017

p. $377-396$
} 
agrícolas. Por fim, será abordada a relação demanda e oferta de instrução à população de uma das colônias - Afonso Pena - no que se pretende um estudo de caso da relação entre instrução, população e território ${ }^{4}$.

\section{Territorialização e planejamento urbano}

No estudo das relações entre espaço e ocupação humana a geografia política busca estabelecer distinções entre espaço, entendido como meio físico e território, referente à sua ocupação, e transformação por grupos populacionais ${ }^{5}$ (Sack, 1996). Tal processo de apropriação do território é definido como territorialidade ou "o esforço de um grupo social para ocupar, usar, controlar e se identificar com uma parcela específica de seu ambiente biofísico, convertendo-o assim em seu território" (Litle, 2002, p. 3).

Castro (2006) destaca o embate entre os diferentes atores sociais pela territorialidade por "um conjunto de práticas e suas experiências materiais e simbólicas capazes de gerarem a apropriação e permanência de um dado território por um determinado agente social, o Estado, os diferentes grupos sociais e as empresas" ( $p$. 251). O autor relaciona esta dimensão de apropriação do território à construção de identidades sociais ao longo de um processo histórico. Sack (1996) ressalta também que a análise da territorialização envolve necessariamente contemplar as relações entre as dimensões física e histórica.

Numa perspectiva histórica o estudo dos espaços no diálogo com a geografia marca especialmente a produção dos Annales. O livro de Lucian Febvre La terre et le evolution humaine (1922) teria profundo impacto na escrita da seminal obra de Fernand Braudel (1949) O Mediterrâneo e o mundo mediterrâneo em que o autor assenta o estudo histórico da região nas relações entre o meio físico, volume 1 , sua apropriação por sociedades, volume 2 , e indivíduos, volume 3 , no que define como um tempo geográfico, um tempo social e um tempo individual (Braudel, 2005).

Se Braudel (2005) tomou como objeto o estudo da história de ocupação de uma região geográfica, a produção posterior concentrou-se nas investigações sobre as cidades. Estas foram marcadas, inicialmente, por uma apreensão unívoca do termo, superada na produção posterior que cada vez mais busca contemplar como, em condições sociais e econômicas distintas, as configurações urbanas se singularizam (Barros, 2006) . $^{6}$

$\mathrm{Na}$ escrita da história das cidades destacam-se as investigações sobre as radicais transformações ocorridas nas metrópoles européias a partir da Revolução Industrial, no que se define por revolução urbana, marcada pelo deslocamento do rural para o urbano como espaço dominante de ocupação, especialmente na Inglaterra (Sennet, 2008). Afirma-se uma relação entre industrialização e urbanização que se tornou referência para apreensão de emergência das metrópoles que estudos posteriores demonstraram não ser passível de generalização (Bresciani, 2002).

\footnotetext{
${ }^{4}$ É importante destacar as interlocuções com as pesquisadoras Alessandra Schueller e Irma Rizzini, que vêm contemplando questões semelhantes nos estudos sobre o Rio de Janeiro.

${ }^{5}$ Geógrafos com Milton Santos (1996) utilizam diferentemente os conceitos. Para o autor a apropriação do território, entendido como meio físico, pela população cria o espaço.

${ }^{6}$ Jacques Le Goff, em Por amor às cidades (1998), constrói uma análise que põe em diálogo aspectos das cidades medievais e contemporâneas, destacando permanências e deslocamentos. 
Atravessam as investigações históricas eixos analíticos como privado, público, rural, urbano, ocupação e mobilidade que vêm sendo tratados de maneira cada vez menos dicotômica ${ }^{7}$. Os estudos se voltam para a apreensão dos significados históricos da experiência urbana, conferindo destaque às identidades sociais dos sujeitos deste processo.

Nos últimos anos, segundo Kingston (2010), ocorreu uma redescoberta pela história do estudo dos espaços e lugares, o que define como transformação nas investigações sobre o tema: spatial turn. O uso do termo redescoberta visa a resgatar a longa tradição de investigações, ao mesmo tempo em que marca a diferença na produção contemporânea, calcada no recurso a novas tecnologias que permitem visualizar a dinâmica histórica da ocupação dos espaços ${ }^{8}$.

As investigações históricas sobre as cidades ancoram-se no diálogo, não tanto com a geografia, mas com autores dos campos do urbanismo e sociologia urbana ${ }^{9}$. Um tema que se destaca é a investigação sobre emergência e transformação de espaços urbanos, definidos não por crescimento natural, mas por sua planificação. Bresciani (2002) indica que já no século 18 as cidades ideais, ou projetos de cidades idealizadas, ocupavam o imaginário europeu, informando a criação de San Petersburgo, modelo histórico de intervenção e domínio da natureza.

Já ao longo do século 19 os planos das cidades imaginadas voltam-se para a solução dos problemas sociais existentes. O crescimento desordenado das grandes metrópoles, como Londres e Paris, com os problemas de salubridade, habitação, violência e mobilidade consequentes, levaram à elaboração de reformas urbanas. Informadas por saberes técnico-científicos, destacadamente no diálogo entre a engenharia e o sanitarismo, a planificação iria dar origem à ciência do urbanismo no século 20 .

As reformas urbanas do período configuraram-se como uma das principais estratégias de intervenção não apenas no espaço, mas nas populações que os ocupavam. Tal fenômeno teve início com a paradigmática intervenção desenvolvida pelo barão Haussman em Paris, a qual serviu de modelo para outras ações ao redor do mundo, como São Petersburgo e Nova lorque. Os princípios urbanísticos que regiam tal reforma eram o alargamento e retificação de ruas, o saneamento de bairros insalubres e iniciativas de embelezamento fundadas numa estética neoclássica laica.

No Brasil a reforma Pereira Passos (1903-1906) no Rio de Janeiro, bem como os projetos de expansão urbana de Santos (1896-1910), Vitória (1896), Recife (1910-1914), Porto Alegre (1913), Parayba do Norte, atual João Pessoa (1913) ${ }^{10}$ partilhavam do mesmo paradigma. Uma perspectiva mais radical de intervenção urbana configurou-se na criação de cidades planejadas como La Plata, na Argentina, Washington nos EUA e Belo Horizonte no Brasil ${ }^{11}$.

\footnotetext{
${ }^{7}$ Para uma historiografia das cidades vide o verbete Urbano em Burguiere (1993); assim como Raminelli (2007).

8 Vide The spatial history project desenvolvido pela Universidade de Stanford, que contempla o estudo da ocupação do Rio de Janeiro: http://web.stanford.edu/group/spatialhistory/cgi-bin/site/index.php.

${ }^{9}$ Destacam-se, entre outros, MUMFORD, Lewis. A cidade na história. São Paulo: Martins Fontes, 1991; CHOAY; Francoise. O urbanismo. São Paulo: Perspectiva, 2000; WEBER, Max. O fenômeno urbano. Rio de Janeiro: Zahar, 1967.

${ }_{11}^{10}$ Vide Nascimento; Krajewski e Britto (2013).

${ }^{11}$ Para uma análise comparativa da criação de Belo Horizonte e la Plata ver Arruda (2011).

Hist Educ (Online)

p. $377-396$
} 
Embora tais reformas tivessem elementos comuns herdeiros da proposta parisiense, as dinâmicas nacionais e locais de governo das populações e gestão do território evidentemente imprimiram distinções características.

Trazendo para o contexto de análise, a cidade de Belo Horizonte constitui objeto privilegiado. Sua criação constitui, tanto expressão de intervenções urbanas que circulavam internacionalmente, quanto o momento histórico do país. Assim é que a construção da cidade afirma-se como materialização do modelo republicano vitorioso, caracterizado pela aplicação de uma racionalidade positivista na organização do espaço, aliada a uma perspectiva segregacionista do governo das populações.

\section{Belo Horizonte: planificação urbana e ocupação territorial}

Belo Horizonte, nova capital do Estado de Minas Gerais, planejada e inaugurada no alvorecer da República (1897), espelhava em seu traçado arquitetônico a perspectiva de ordenação social das elites dirigentes.

A capital foi planejada ${ }^{12}$ em três espaços distintos, desenhados como círculos concêntricos, cuja ocupação populacional seria definida por critérios sociais. A área central, no interior do perímetro da Av. Contorno, que delimitaria o espaço urbano, foi destinada às elites e extratos médios do funcionalismo público, com acesso às edificações e serviços fornecidos pelo Estado, identificados com os padrões de uma metrópole moderna. A área suburbana, para além dos limites desta avenida, seria destinada às camadas populares, sendo caracterizada pela ausência de tais equipamentos e pela construção precária de ruas e moradias, deixadas à cargo da população. Por fim, a zona rural seria constituída por fazendas que já existiam na proximidade do arraial.

É interessante observar como o rural e urbano constituíam não domínios distintos, mas inseridos dentro do mesmo espaço no planejamento da cidade. O modelo buscava integrar as funções de produção, circulação e consumo numa totalidade maior, superando as divisões geográficas tradicionais entre campo e cidade, sob o signo do progresso e civilização.

Para Paula e Monte-Mor (2004) os princípios que regeram a planificação da capital mineira foram salubridade, comodidade e estetização. Avila (2008) também destaca como, coerente com a perspectiva republicana de recurso à linguagem iconográfica na construção de um projeto de Nação, investiu-se na criação de prédios, monumentos e espaços que esteticamente constituíssem expressões de um modelo laico de cidade, em ruptura com a tradição colonial de Ouro Preto, antiga capital.

Porém, tal investimento concentrou-se na zona urbana. Ainda que compreendidas como integradas à cidade, as zonas suburbanas e rural não foram alvos de construção dos mesmos equipamentos, nem dadas condições de transporte que permitissem o acesso às edificações da área central.

Para Alicia Pena (1997, p. 109 apud Vago, 2002), “a zona suburbana foi, na prática, constituindo uma não cidade, sendo ocupada pela população pobre, sendo a porção mais populosa da cidade, encontrando-se em desalinho, tortuosa, estreita, baixa e deselegante - enquanto a outra, modelar, era como o bulevar parisiense aos olhos dos pobres".

\footnotetext{
${ }^{12}$ A planta da cidade foi elaborada antes da definição de seu local de construção.
}

\begin{tabular}{|l|l|l|l|l|l|}
\hline Hist. Educ. (Online) & Porto Alegre & v. 21 & n. 51 & Jan./abr., 2017 & p. 377-396
\end{tabular} 
Tal visão tem sido criticada mais recentemente ${ }^{13}$. Para Aguiar (2006) a região suburbana não constituía uma não-cidade, mas integrava-se ao projeto mais amplo da metrópole, traduzindo em sua espacialidade, o modelo de ocupação preconizado pelas elites dirigentes, que responsabilizava as classes populares por prover condições próprias de moradia, com suporte limitado do Estado ${ }^{14}$.

Como comenta Marins (1998, p. 136), "esse modelo de convívio urbano, trespassado pelos procedimentos de especialização espacial e segregação social, esteve pulsando no cerne dos procedimentos de controle da habitação e vizinhança implementados nas capitais brasileiras do advento da República".

Para além da política de intervenção urbana característica do período, a construção da capital respondia também a demandas regionais de uma nova ordenação política. Se o caráter federativo do novo regime conferia aos Estados, e às suas elites dirigentes, poder significativo, este ganharia efetividade pela coesão das mesmas.

Minas Gerais, historicamente caracterizada pela desagregação da classe política e regionalidade, via-se confrontada pelo novo quadro. A construção da capital tinha em vista conferir unidade e coesão às forças políticas, de forma a superar as disputas regionais. Neste sentido, a construção da nova capital possibilitaria forjar um novo polo político, econômico e intelectual, superando as disputas regionais.

A construção da nova capital respondia também a um plano mais ambicioso que aliava a mudança do local de exercício do poder político e sede administrativa do Estado, fazendo frente a demandas de modernização econômica. A busca de superação das desigualdades regionais e do desequilíbrio sócio-político, concentrado nas zonas da Mata e do sul em função da atividade cafeicultora, teve como estratégia a modernização industrial e agrícola. Neste sentido, a Cidade de Minas, denominação inicial de Belo Horizonte, deveria conjugar atividades industriais e agrícolas, diversificando e modernizando a economia. Para tal, foram dados subsídios aos interessados na implantação de indústrias, ou oficinas, como eram chamadas. Definiu-se, logo posteriormente à planta inicial da cidade, destinar a zona rural à criação de colônias voltadas para modernização e diversificação de atividades agrícolas, as quais seriam habitadas por imigrantes.

Em seus primeiros anos a cidade funcionou mais restritamente como centro administrativo, custando a assumir uma vocação industrial e nunca chegando a estabelecer-se como espaço de modernização agrícola. Em seus 10 primeiros anos a cidade pouco se desenvolveu em termos econômicos, sendo dependente dos subsídios

${ }^{13}$ Belo Horizonte apresenta uma longa tradição de estudos historiográficos. Vide, além dos citados no texto, BARRETO; Abilio. Memória histórica e descritiva de Belo Horizonte. Belo Horizonte, Rex, 1936; MOURÂO, Paulo Krueger. História de Belo Horizonte de 1897 a 1930. Belo Horizonte: Autor, 1970; LE VEN, Michel Marie. As classes sociais e o poder político na formação espacial de Belo Horizonte (18931914). Belo Horizonte: UFMG, 1977. 278f. Dissertação (mestrado em Ciências Políticas). Universidade Federal de Minas Gerais. JULIÃO, Leticia. Belo Horizonte: itinerários da cidade moderna (1891-1920). Belo Horizonte: UFMG, 1992. 245f. Dissertação (mestrado em Ciências Políticas). DULCl, Otavio (org). Belo Horizonte: poder, política e movimentos sociais. Belo Horizonte: C/Arte, 1996; DUTRA, Eliane (org.). BH: horizontes históricos. Belo Horizonte: C/Arte, 1996.

${ }^{14}$ Segundo Veiga (2002) os recursos para construção de casas populares foram inferiores aos destinados às comemorações da inauguração da capital.

\begin{tabular}{|l|l|l|l|l|}
\hline Hist. Educ. (Online) & Porto Alegre & v. 21 & n. 51 & Jan./abr., 2017 p. $377-396$ \\
\hline
\end{tabular} 
do Estado (Aguiar, 2006). Foi a partir das décadas de 1910 e, principalmente de 1920, que a cidade experimentou um aumento populacional significativo, incrementando o setor de serviços e indústria, quando crescia a taxas de $10 \%$ ao ano (Aguiar, 2006).

O plano inicial privilegiava na área central a oferta de equipamentos, serviços e lazer, como o Parque Municipal, praças, secretarias de Estado, cemitério, igrejas, hospitais e escolas. Já a área suburbana apresentava características diferenciadas, com lotes mais amplos e ausência de serviços públicos. Tinha-se como previsão um movimento de ocupação do centro para a periferia, em que a cidade, por ação do progresso e da ocupação do território, estenderia os equipamentos às regiões periféricas.

Porém, os condicionantes econômicos impuseram uma ocupação territorial diferenciada. Enquanto o preço dos terrenos teve alta especulação na zona urbana, na suburbana e rural a existência de áreas maiores e mais baratas levou a uma maior ocupação pela população ${ }^{15}$. Tal processo foi de certa forma fomentado pelo governo local, ao permitir a divisão dos lotes nas zonas suburbanas, possibilitando a construção de vilas, o que não ocorreu na zona urbana. Segundo o censo de 1912 a população da cidade estava assim distribuída: urbana 12.033 (32\%), suburbana 14.842, rural 11.947 (ambas $78 \%$ ), totalizando 38.822 (Recenseamento de 1912).

Ou seja, diversamente do que foi planejado por ocasião da construção da cidade, sua territorialidade definiu-se num movimento da periferia para o centro. No fim dos anos 1920 Belo Horizonte apresentava-se como uma cidade curiosamente vazia no centro e adensada na sua primeira periferia e assim permaneceu até os anos 1970 (Aguiar, 2006).

No dizer de dois arquitetos na década de 1930, "a Capital não se tornou densa, de início, como acontece às grandes cidades. [...] Enquanto as ruas do centro da cidade, em sua maior parte, apresentam casas de vastos quintais, há nos bairros um formigamento de construções tendentes a, cada vez mais, ampliar a área da cidade" ( apud Borsagli, 2011, p. 17).

Esta territorialização configurou-se como problema, não apenas pela não efetivação do plano inicial, mas também pelas demandas provocadas. Segundo Pádua e Monte-mor (2004), as solicitações das populações situadas fora do perímetro da região urbana concentraram-se, a partir da década de 1910, em serviços como transporte, saneamento e energia. A arrecadação municipal mostrava-se insuficiente e optou-se, a partir de 1914, pela transferência destes serviços à iniciativa privada, com privatização dos serviços de bonde e energia. Ou seja, o investimento estatal na criação de uma infra-estrutura urbana restringiu-se, em termos gerais, à região central ${ }^{16}$.

Observa-se que, em decorrência da precariedade do orçamento municipal, determinada pela perda da arrecadação, aumento populacional muito além do previsto , queda do preço do café, a cidade teve que diminuir o ritmo de investimento na sua

\footnotetext{
15 "Os prédios da zona urbana, além de apresentarem um valor absoluto médio cerca de três vezes superior (tanto para venda quanto para locação), ainda eram relativamente mais caros se estabelecermos um índice entre o valor dos aluguéis de cada área e o valor de compra dos imóveis [...]. Sabe-se que a ocupação da zona urbana de Belo Horizonte, obedeceu a uma série de normas rígidas de cunho segregacionista, o que explica o alto preço dos aluguéis encontrado. Aqueles que tinham condições de se instalar na zona urbana eram forçados a desembolsar maiores quantias pelo privilégio, em vista do alto custo das construções. A alternativa seria habitar fora do perímetro da Avenida do Contorno, mesmo se sujeitando à precariedade de infraestrutura" (Gough, 1994, p. 52).

${ }^{16}$ Esta transferência não significou uma melhoria dos serviços, ao contrário, as reivindicações por melhores condições de moradia e transporte eram frequentes nos jornais da época e registros memorialísticos.
} 
consolidação. Acresce-se a estas questões a falta de autonomia política do município que até 1947 esteve submetido aos governos do Estado, que indicavam os prefeitos. Ou seja, a cidade teve que adequar-se aos interesses políticos das oligarquias estaduais (Dulci, 1996). Todas estas condições impuseram uma precarização na oferta de infra-estrutura, o que impactou especialmente os moradores das regiões periféricas à área central, destacadamente trabalhadores nacionais e imigrantes.

\section{Imigrantes e território}

Se não estava prevista no plano original da cidade, a criação das colônias agrícolas respondia às estratégias de modernização agrícola do Estado e não se restringia à nova capital, onde foi denominada zona colonial. Também Juiz de Fora e São João del Rei tiveram criadas colônias agrícolas situadas nas fronteiras do espaço urbano.

Tal política não era específica do Estado, pois colônias agrícolas foram massivamente implantadas também no Sul do país. Porém, estas em sua maioria ocupavam as regiões rurais distantes das cidades, tendo sido ali amplamente vitoriosa a estratégia de desenvolvimento de atividades agrícolas por imigrantes que diversificaram e modernizaram a produção naqueles Estados (Rodrigues, 2009).

Já no caso mineiro e, especialmente de Belo Horizonte, as colônias constituíram um empreendimento de curta duração, que nunca respondeu à demanda de modernização agrícola. Porém, sua ocupação deixou significativas marcas na identidade sócio-cultural da população da cidade.

A implantação foi resultado do casamento entre as políticas agrária e imigratória. As colônias agrícolas de Belo Horizonte foram concebidas, tanto na direção da ocupação territorial, quanto na de produção e oferta de gêneros alimentícios para os moradores da capital. A mudança significou um remanejamento do território da cidade, trazendo a zona rural para mais perto da zona urbana e misturando-se à suburbana. No dizer de Aguiar (2006), "o projeto de planificação do espaço no limite entre o rural e urbano traduzia o modelo de planejamento em curso. As colônias foram concebidas tanto a partir de uma exterioridade em relação ao espaço urbano, como de uma integração, conferindo aos moradores uma funcionalidade social como produtores de gêneros alimentícios" (p. 62).

A política imigratória mineira foi intensa e curta. Em 1890 foi criada a Repartição de Terras e Colonização, que determinou a arregimentação de imigrantes, especialmente italianos interessados em emigrar para o Estado de Minas Gerais, tendo como atrativo seu clima ameno, localização geográfica, condições favoráveis de trabalho e leis de proteção aos estrangeiros ${ }^{17}$, itens presentes nas propagandas divulgadas em folhetos (Borsagli, 2011). O fluxo cresceu rapidamente: foram 200 imigrantes em 1892 e 10.000 em 1894 (Rodrigues, 2009).

\footnotetext{
17 Questão importante, porque neste período já se faziam presentes denúncias das péssimas condições de trabalho encontradas por imigrantes italianos, especialmente nas fazendas de café, onde substituíam a mão de obra escrava. 
Em termos nacionais Minas Gerais foi o terceiro Estado na recepção de imigrantes italianos, atrás de São Paulo e Rio Grande do Sul. A política imigratória do Estado assemelhava-se ao Estado sulista, na medida em que, aos recém-chegados, eram destinadas pequenas áreas agrícolas, enquanto em São Paulo o trabalho na lavoura do café em grandes propriedades era o destino ${ }^{18}$.

O território das colônias caracterizava-se pela precariedade dos equipamentos já que, a princípio, constituiriam um núcleo rural: esta região já era ocupada por fazendas e cafuas. A descrição da topografia da cidade presta-se à caracterização da paisagem das regiões periféricas onde estas estavam situadas, "marcada por uma rede hidrográfica natural do sítio, pequenos cursos d agua que drenam vales estreitos em meio a uma topografia variada caracterizada por colinas e terrenos íngremes" (Nascimento; Krajewsi; Britto, 2013, p. 117).

Para além da atividade agrícola os imigrantes foram envolvidos na construção da nova capital. O plano arquitetônico referenciado em padrões estéticos Art Noveau demandava mão de obra especializada. Assim é que praticamente $50 \%$ dos operários envolvidos na construção da capital era constituída por imigrantes, com predomínio de italianos com experiência em construção civil.

Observa-se que como $13,8 \%$ da população de Belo Horizonte fosse composta por estrangeiros e apenas $4 \%$ da população do município residisse nas colônias agrícolas em 1904, grande parte da população imigrante da capital vivia fora das colônias (Aguiar, 2006). Ou seja, a associação entre imigração e construção de colônias agrícolas não se efetivou completamente.

A primeira colônia, Barreiro, foi criada em 1895, mas não vingou, tendo sido abolida em 1899. Outras duas colônias foram criadas em 1896 e implantadas em 1898, Carlos Prates e Córrego da Mata, depois denominada Américo Werneck. As outras três foram criadas em 1899, sendo nomeadas Afonso Pena, Bias Fortes e Adalberto Ferraz. A colônia Afonso Pena apresentava uma peculiaridade quanto à sua localização, pois se situava nos limites da Avenida do Contorno, marcando uma fronteira entre a urbanidade da região central e a zona rural da colônia.

Inicialmente a política de construção de colônias agrícolas articulava-se à política imigratória. Os terrenos das colônias deveriam ser doados ou vendidos a baixo preço aos imigrantes recém-chegados, que desenvolveriam atividades de lavoura. Embora no texto legal as colônias agrícolas fossem preferencialmente destinadas a tal população, a nacionalidade mais presente foi a brasileira: em 1903 os nacionais compunham $47,5 \%$ dos habitantes da zona colonial e em 1910 45\%. A seguir vinham os italianos: $37,2 \%$ em 1903 e 39,4\% em 1910.

Os italianos sempre estiveram como o grupo imigrante mais numeroso em Belo Horizonte. Em 1905 75\% dos estrangeiros na cidade eram dessa nacionalidade e em 1920 61\%. Portugueses e espanhóis vinham a seguir (Rodrigues, 2009).

A população oscilou significativamente ao longo da existência das colônias. Estas contavam em 1900 com 1.137 pessoas, entre brasileiros e imigrantes, sobretudo italianos, população que se reduziu pela metade em 1904 - 625 pessoas -, voltando a crescer e atingindo a população de 1.162 indivíduos em 1910. Formavam uma parte significativa da

18 Segundo Rodrigues (2009), em regulamento promulgado em 1890, os fazendeiros que dividissem seus latifúndios para formação de colônias receberiam vantagens e subsídios do governo estadual.

\begin{tabular}{|l|l|l|l|l|l|}
\hline Hist. Educ. (Online) & Porto Alegre & v. 21 & n. 51 & Jan./abr., 2017 & p. 377-396
\end{tabular} 
população da cidade, haja vista que em 1900 viviam na capital 13 mil pessoas e 17 mil em 1905. A porcentagem da população da zona colonial na capital variou, portanto, de 8\%, em 1900, a 4\%, em 1905 (Rodrigues, 2009).

A oscilação da população das colônias e sua redução na primeira década republicana relaciona-se à peculariedade do Estado no desenvolvimento de uma política imigratória. Se o fluxo de estrangeiros para Minas Gerias foi intenso na última década do século 19, foi mais curto e menos significativo que em outros Estados em função de, entre outros fatores, sua onerosidade ${ }^{19}$ e diminuição do preço internacional do café (Botelho, 2007).

Observa-se que se o objetivo de povoamento do território às margens da zona urbana foi bem sucedido, o mesmo não ocorreu em relação à vocação agrícola. Verificase a presença de trabalhadores residentes das colônias como operários ou prestadores de serviços aos demais moradores da cidade. Tal fator, aliado à falta de apoio do governo para desenvolvimento de atividades agrícolas, levou à incorporação das colônias ao núcleo propriamente urbano da capital na década posterior.

$\mathrm{O}$ investimento estatal mostrou-se errático e insuficiente. Mesmo estando previsto no regulamento de criação das colônias a oferta de equipamentos básicos e infra estrutura, tal não ocorreu. Os lotes foram comprados pelos imigrantes e não doados, sendo os mesmos responsáveis pela edificação das ruas e serviços sanitários. Nem mesmo o registro dos terrenos foi efetivado. Contrastando com o núcleo central que recebeu dos governos as condições de moradia, não apenas em termos de infraestrutura, mas de equipamentos, nenhum espaço público foi edificado nas colônias pelo poder público inicialmente.

A ausência do Estado foi registrada mesmo no relatório governamental: "As colônias vão em grande prosperidade, apesar de terem tido poucos favores do Governo, pois os colonos construíram as casas às sua custa, e pelas escrituras devem pagar os terrenos de acordo com as cláusulas estipuladas . O governo tem prestado alguns auxílios com a extinção de formigas nos lotes coloniais" (Relatório, 1902, p. 52).

Progressivamente as zonas coloniais foram incorporadas à zona suburbana, sendo os lotes divididos, criando-se vilas que permitissem a ocupação por uma população maior, que não tinha como arcar com os preços dos lotes da região urbana. Em termos legais as colônias agrícolas foram extintas e incorporadas à zona suburbana em 1911 e 1912, o que permitiu o investimento em sua urbanização.

Tal mudança configurou-se no interior de deslocamentos das populações no movimento de territorialização da cidade, definidos por mobilidade social e política urbana. Assim é que muitos imigrantes, nem todos de origem popular, deslocaram-se para os bairros mais centrais ou vieram a ocupar regiões mais valorizadas das áreas ditas suburbanas. Já os grupos populares ocuparam espaços periféricos configurando regiões de alta concentração demográfica, em oposição às áreas vazias da região central.

\footnotetext{
${ }^{19}$ A imigração para Minas Gerais foi subsidiada pelo governo, sendo pouco frequente a imigração voluntária (Botelho, 2007). 


\section{Colônias agrícolas e escolarização}

O direito à educação primária gratuita nas colônias era previsto pela lei n. 281, de 16 de setembro de 1899, que regulamentava a criação de uma escola mista em cada colônia agrícola cuja população escolar fosse superior a vinte crianças e com uma frequência mínima de 15 alunos.

O texto legal considerava a especificidade dos núcleos rurais, com densidade populacional inferior aos núcleos urbanos, em que era exigida uma população mínima de 30 crianças em idade escolar, embora fosse mantida a exigência de uma frequência significativa de $75 \%$. O problema da infrequência escolar, já presente na período imperial, teve continuidade, especialmente entre as classes populares e nos espaços rurais, onde a necessidade da participação das crianças nas atividades de trabalho se fazia mais presente, bem como a aquisição da cultura escrita menos significativa. Mas cabe destacar que, segundo Rodrigues (2009), em Minas Gerais ocorreu um aumento significativo de $30 \%$ na frequência nas primeiras décadas republicanas.

Apesar do regimento que criou as colônias prever que "na sede da colônia se construirá um prédio modesto para uma escola mista, desde que seja oportuno" (Coleção, 1899 , art. 12, p. 67), tal não ocorreu nos seis primeiros anos de funcionamento das colônias agrícolas da capital.

Observa-se que o texto legal mostra-se pouco assertivo na definição da responsabilidade estatal na oferta de instrução e no atendimento ao direito da população. O uso do termo modesto revela uma dimensão de contraste com a política de concessão de grandes espaços nas áreas centrais para construção de escolas privadas, inicialmente concebidas como responsáveis privilegiados pela oferta da instrução primária (Faria Filho, 2001). Também a observação de que tal edificação não seria obrigatória, mas apenas oportuna, demonstra o caráter ambíguo da responsabilidade estatal.

A demanda por escola fazia-se presente naquela população. Nos jornais italianos da capital, dentre as reclamações e reinvindicações, este era o tema mais frequente. $\mathrm{Na}$ verdade pretendia-se uma escola italiana que ensinasse a língua e valores relacionados àquela nacionalidade (Costa, 2005; Nicácio; Myrha, 2015).

A inexistência de escola pública nos seis primeiros anos de funcionamento das colônias fez com que esta população arcasse, tanto com a abertura de uma escola na colônia Carlos Prates, a mais habitada, financiada pelos próprios moradores, quanto instituísse a Escola Italiana, ambas em 1902. A abertura da escola pública efetivou-se em 1903, após abaixo assinado encaminhado pelos moradores da colônia Carlos Prates ao secretário do Interior e ao Inspetor de Terras e Colonização, no qual solicitavam a construção de uma escola de instrução primária gratuita para suas crianças, já que até então foram os responsáveis pela escolarização de seus filhos (Rodrigues, 2009). Além desta, foram criadas quatro cadeiras mistas nas demais colônias (decreto n. 1.585, de 14 de março de 1903). Observa-se, portanto, um movimento de maior responsabilização do Estado pela instrução, em que não apenas a reivindicação foi atendida, como estendida às demais colônias.

A cidade passou então a contar com 11 escolas privadas, que receberam doação de terrenos e outros subsídios, oito cadeiras urbanas, quatro do sexo feminino e quatro do masculino, 5 cadeiras mistas nas colônias e nenhuma na zona suburbana. Tal dado é interessante e demanda problematização. $O$ atendimento privilegiado de escolas às zonas 
urbanas, ocupadas pelas camadas médias e elites, e zonas coloniais, ainda significativamente constituída por imigrantes, respondia a uma pressão maior de instrução por parte desta população, a uma política discricionária, ou a ambas?

A população das colônias apresentava elevados índices de letramento em comparação com os índices nacionais, que indicam $20 \%$ da população como alfabetizada. Segundo dados oficiais, em $1903,75 \%$ da população das colônias agrícolas sabia ler e escrever. No ano de 1910 tal índice decresceu para 61,3\%. Já o número dos que não sabiam ler e escrever subiu de 25\% em 1903 para 38,7 \% em 1910 (Aguiar, 2006). Tais dados devem ser vistos com cuidado. Com aponta Ferraro (2009), o censo de 1910 revelou-se problemático, em que o cômputo concentrou-se nas áreas urbanas, deixando de registrarem-se os índices das zonas rurais.

Ainda que com cautela cabe debruçar-se sobre estes índices para melhor compreender a relação desta população com a cultura escrita. Como apontado anteriormente a população de brasileiros habitantes das colônias aumentou ao longo do período. O índice de letramento era significativamente maior entre os imigrantes. Assim é que o aumento da população nacional fez possivelmente restringir os índices de letramento.

Outro recorte a ser sublinhado é o geracional. Como era significativa a população de menos de 12 anos $^{20}$, muitos adultos provavelmente foram alfabetizados no país de origem, o que não ocorreu com a geração posterior. Seria este dado indicativo da insuficiência de espaços de escolarização?

A valorização da instrução pela população imigrante relacionava-se também com a sua identidade de classe. Os estudos sobre a história dos movimentos operários da cidade (Dutra, 1988) indicam que as sociedades mutualistas davam destaque à instrução e educação dos trabalhadores como condição de melhoria nas condições de vida e maior consciência social. A mais importante, a Sociedade Operária Italiana, criada em 1896, contribuiu para financiamento da escola italiana criada na colônia Carlos Prates, antes que fosse implementada a escola pública, valorizando tanto o acesso à instrução, quanto a preservação da língua e da cultura.

Verifica-se, portanto, um movimento geográfico oposto na ocupação da cidade pela população e a oferta da instrução, à semelhança de outros serviços públicos. Enquanto, como apontado acima, a ocupação populacional apresentou um movimento da periferia para o centro da cidade, a oferta de instrução pública fez-se no sentido inverso ${ }^{21}$.

Peterson (1983) identifica o mesmo processo na história da escolarização norteamericana em que, ao invés de concentrar os recursos nos segmentos mais pobres da população, estes foram ignorados até o provimento de espaços educativos considerados adequados às camadas médias. O atendimento às demandas escolares das camadas

${ }^{20}$ Segundo Botelho (2007) as crianças de menos de 10 anos constituíam a maioria da população imigrante nos registros da Hospedaria de Imigrantes de Juiz de Fora.

${ }^{21}$ Há uma significativa produção sobre a educação em Belo Horizonte no período. Além dos trabalhos de Veiga (2002), Vago (2002), Faria Filho (2000), Rodrigues (2009), destacam-se o dossiê Cidade e educação: BH ano 100. Educação em Revista n. 26, 1997, p. 23-112; NOGUEIRA, Vera Lúcia. A escola primária noturna em Minas Gerais (1891-1924). Belo Horizonte: Mazza, 2012; NOGUEIRA, Priscila. A fim de arrancar da ignorância e do erro pequeninos seres: as caixas escolares em Belo Horizonte (19111918). Belo Horizonte: UFMG, 2013. 176f. Dissertação (mestrado em Educação). Universidade Federal de Minas Gerais. 
pobres e racialmente discriminadas no contexto norte-americano foi não apenas posterior, mas em condições mais precárias de instalação, o que podemos compreender como semelhante ao caso brasileiro e, especificamente, da capital mineira.

A partir de 1903 houve significativo investimento estatal na construção e manutenção de escolas nas colônias, como se pode apreender dos relatórios dos inspetores, que destacam a adequação das instalações e dos materiais didáticos. Os números das escolas dos núcleos coloniais, se comparados ao conjunto da cidade para o ano de 1904, demonstram que, dos alunos matriculados nas escolas públicas da capital no primeiro semestre, 317 matricularam-se nas escolas das colônias, ou seja, 38,4\% dos alunos da capital estavam nas escolas dos núcleos. Tal dado, como observado por Rodrigues (2009) indica a presença não apenas de crianças das colônias, mas de moradoras da zona suburbana, dada a ausência de escolas públicas naquela região.

Em 1906 o texto da Reforma João Pinheiro, que instituiu os grupos escolares no Estado, no que se refere às colônias, repetia o mesmo do regulamento anterior, com uma pequena modificação no parágrafo $2^{\circ}$ do artigo 13 , onde afirma-se que "na sede da colônia se construirá um prédio modesto para uma escola mista", retirando-se o termo oportunidade da construção presente no regulamento anterior. Isto indica que, em termos legais, o Estado assumiu a obrigatoriedade de construção destas edificações.

Uma questão destaca-se. Se a historiografia da cidade aponta no período a ausência de investimento na infra-estrutura das zonas suburbana e colonial (Paula; Monte-Mor, 2004), diferentemente dos demais serviços, verifica-se o investimento na escolarização dos moradores desta região. Um exemplo encontra-se no relatório do prefeito Benjamim Jacob em 1906, que registra as despesas com serviços públicos e sua localização. De todas as despesas arroladas apenas a extensão da tubulação para abastecimento de água à escola pública da colônia Bias Fortes visava as populações situadas fora da zona urbana (1907, p. 15). No mesmo relatório registra-se a construção de casas para escolas primárias nas colônias Bias Fortes, Adalberto Ferraz, além do grupo escolar, escolas singulares e escola infantil na região central da cidade. Verifica-se, portanto que, ainda que concentrados na região urbana, foram destinados recursos para escolas públicas nas colônias e, posteriormente, à zona suburbana. Ou seja, ainda que não privilegiadas na oferta da instrução houve, por parte dos governos municipais, uma destinação de recursos para instrução pública da população moradora fora da zona urbana, o que não ocorreu em relação a serviços como transporte - não haviam bondes que atendiam a estas regiões -, energia elétrica e água - problema constantemente evocado nos jornais locais.

Ainda assim verifica-se que a localização territorial das colônias dificultava o acesso e frequência das crianças ali moradoras às escolas. No regulamento de 1899 as escolas das colônias podiam apresentar índices inferiores de matrícula e frequência, dada sua caracterização como zona rural. O decreto n. 2.130, de 27 de novembro de 1907, definiu que "declara urbanas as cadeiras mistas isoladas, situadas nos subúrbios desta capital, criadas pelo dec. n. 1585 de 15 de março de 1903" (coleção, 1907 apud Rodrigues, 2009, p. 175). Esta mudança conferiu a mesma identidade às escolas situadas na zona urbana e colonial da cidade, o que revela uma compreensão da indiferenciação das mesmas, demandando iguais exigências de matrícula e frequência. 
Esta mudança trouxe alguns impactos indiretos, como se apreende do relatório do inspetor regional Antonio Gomes, em 18 de outubro de 1911: "Não me canso de levar ao conhecimento de Vossa Excelência o grave inconveniente do horário matinal que poderá ser útil nas zonas urbanas, mas não nas colônias rurais. Para elas convergem crianças de grandes distâncias, que só com muito sacrifício poderão chegar à classe à hora certa" $(\mathrm{s} / \mathrm{p})$.

No caso da colônia Afonso Pena tal dificuldade foi acentuada. Criada em 1899 e incorporada à zona suburbana em 1912 a Colônia Afonso Pena apresentava baixa ocupação, na comparação com as demais. Teve inicialmente destacado papel na produção de alimentos, atividade que foi aos poucos perdendo importância, sem que viesse a desenvolver atividades industriais como ocorria nas outras colônias (Aguiar, 2006).

Sua população teve significativa flutuação, tendo variado de 268 em 1900, diminuindo para 87 em 1905, aumentando para 169 em 1910. Predominavam os brasileiros e, em menor número, italianos. Como nas demais, a ocupação concentrava-se em núcleos familiares, com significativa presença de menores de 10 anos (Aguiar, 2006, Rodrigues, 2009).

No que se refere à instrução primária a escola mista criada em 1903 contou com uma flutuação nos índices de frequência, que iriam decair progressivamente. Mesmo assim no ano de 1912 a população solicitou à Secretaria do Interior a abertura de uma nova escola primária em um terreno doado por um morador. Esse pedido foi acompanhado de uma lista contendo assinaturas de 35 colonos que possuíam 50 filhos em idade escolar e "que não gozavam do benefício da instrução primária, pelo fato de que a única escola na colônia localizar-se em uma região distante, que não possuía nenhuma estrada de acesso" (relatórios de Inspeção Técnica, 1912). Esta breve descrição corresponde às condições da colônia naquele período, com um terreno irregular, sem ruas demarcadas e atravessadas por um córrego, possivelmente o abaixo assinado referia-se ao córrego do Leitão canalizado em 1928, que dificultava a travessia por crianças pequenas. Ou seja, mesmo havendo escola, esta era inacessível, o que certamente contribuiu para a baixa frequência e subsidiou o envio do abaixo assinado.

$\mathrm{O}$ fato dos moradores oferecerem o terreno para a escola deveria privilegiar o atendimento, de acordo com o regulamento: "Para a disseminação de escolas isoladas e de grupos escolares, serão de preferencia attendidas as localidades que corresponderem aos intuitos do governo, offerecendo ao Estado predio onde o ensino se possa exercer de modo conveniente e efficaz" (Minas Gerais, 1906, p. 7). O artigo 6 previa que "na execução de seu plano de ensino, o governo, para instituição de escolas de qualquer espécie, grupos escolares etc., dará preferência às localidades que o auxiliarem eficazmente já por sommas em dinheiro, já por dádivas de predios, terrenos ou materiaes" (Minas Gerais, 1906, p. 7).

Tal prioridade comprometia o acesso à instrução pelas camadas mais desfavorecidas, incapazes de contribuir para manutenção dos núcleos escolares. No caso da colônia Afonso Pena a ação de escrita e encaminhamento do abaixo assinado, bem como a cessão do terreno por um dos pais interessados, demonstram o investimento da população na instrução num período em que a valorização dos terrenos na cidade foi significativa. 
Vigorava então o Regulamento da Instrução de 1911, promulgado pelo presidente Bueno Brandão, que procedeu a uma ampla revisão dos regulamentos anteriores, especificando normas para os diferentes graus da instrução. Nele constava o decreto $n$. 3.191, de 9 de junho de 1.911, que instituía a criação de até duas escolas nas áreas rurais e de colônias, desde que essa se inserisse no quesito de povoações com um mínimo de vinte casas habitadas, 50 crianças ou mais em idade escolar.

O pedido da construção de uma nova escola foi negado pelo inspetor regional de ensino Antônio Gomes Horta, justificando que a região já tinha uma escola mista funcionando e que a frequência e matrícula no presente ano eram diminutas. A tabela a seguir confirma a justificativa dada à negação do pedido.

Tabela 1 -

Tabela de matrícula e frequência da Escola da Colônia Agrícola Afonso Pena.

\begin{tabular}{|c|c|c|}
\hline Escola na Colônia Afonso Pena & Alunos matriculados & Frequência \\
\hline $2^{\circ}$ Semestre de 1910 & 72 & 22 \\
\hline $1^{\circ}$ semestre de 1912 & 48 & $\begin{array}{c}13,32,30 \\
\text { (fevereiro, março, abril) }\end{array}$ \\
\hline
\end{tabular}

Fonte: Aguiar (2006, p. 92) e relatório de inspeção técnica do ensino, 1910 e 1912, APM.

Já nas demais quatro colônias que contavam com um índice de frequência superior, tal demanda foi atendida com abertura de uma segunda escola. Verifica-se que, a se considerar os dados do abaixo-assinado, um número significativo de crianças não foi contemplado com a instrução pública em razão da localização das moradias.

Fatores significativos para a população como distância da escola e condições de acesso não eram considerados pela lógica estatal, centrada na relação entre matrícula e frequência. No caso apresentado tal lógica é confrontada com a experiência social dos moradores, em que à semelhança de outros locais no Brasil alia-se a baixa frequência à insuficiência da oferta.

\section{Conclusão}

Para entender os processos históricos de acesso à instrução cabe ter em vista não apenas as distintas identidades sociais das populações atendidas, em sua tensão com o ideário de universalização da educação primária, mas considerar que tais dinâmicas inscrevem-se em espaços geográficos. Se o acesso à escola mostra-se distinto nos núcleos rurais e urbanos, nestes as condições de instrução relacionam-se às posições das populações na cidade, hierarquicamente definidas.

Pode-se observar que, no decorrer da Primeira República, as populações buscaram fazer frente às políticas segregacionistas e excludentes, tanto por meio de movimentos organizados, quanto reivindicando serviços como transporte, melhores condições de moradia por petições, abaixo assinados e reclamações em jornais. 
No entanto, faz-se pouco presente um olhar para as demandas sociais por instrução por parte das populações envolvidas, entendidas como atores sociais deste processo ${ }^{22}$. Assim é que os grupos sociais tem sua presença na produção historiográfica mais recente sobre o período preponderantemente apresentados como objeto da ação educacional do Estado e não como protagonistas do processo de escolarização das novas gerações.

Tal privilegiamento decorre, por um lado, pela significativa presença de fontes nos arquivos documentais, centradas na ação do Estado, com poucos registros das demandas sociais e dos embates em torno dos diferentes projetos de instrução em curso. Por outro, a preponderância do recurso às fontes governamentais, sem uma problematização das mesmas, tem levado muitas vezes a uma reprodução do discurso do Estado. Como afirma Demartini (2006),

as teias de significados que acompanharam a implantação da instituição escolar são muito mais complexas, não podemos pensar apenas naquelas explícitas e implícitas no modelo de escola proposto pelo Estado em nome da população. É preciso verificar o outro lado, o lado da demanda, dos sujeitos envolvidos no processo, para aprendê-las e compreendê-las. ( $p$. 93)

Neste sentido o estudo do processo histórico de escolarização no Brasil demanda, para sua melhor compreensão, a construção de cartografias da instrução, de forma a apreender a relação entre pertencimento social das distintas populações e ocupação do território, num país cujas desigualdades inscrevem-se também nos espaços. $\mathrm{O}$ acesso à instrução cabe ser apreendido no interior de lutas por territorialização.

\section{Referências}

AGUIAR, Tito Flávio Rodrigues. Vastos subúrbios da nova capital: formação do espaço urbano na primeira periferia de Belo Horizonte. Belo Horizonte: UFMG, 2006. 312f. Tese (doutorado em História). Universidade Federal de Minas Gerais.

ARQUIVO PÚBLICO DA CIDADE DE BELO HORIZONTE. Coleção leis e decretos do Estado de Minas Gerais. 1847-1952 (CC.02/). 1999

ARQUIVO PÚBLICO MINEIRO. Relatórios de inspeção técnica do ensino. Belo Horizonte, 1910, 1912.

ARQUIVO PÚBLICO MINEIRO. Relatórios de inspeção técnica do ensino. Belo Horizonte, 1910, 1912.

\footnotetext{
22 Destacam-se nesta perspectiva, além de citados neste texto, os seguintes trabalhos sobre demanda de educação na Primeira República: SOUZA, Rosa Fátima. O direito a educação: lutas populares pela educação em campinas. Campinas: Unicamp, 1998; FARIA FILHO, Luciano. República, trabalho e educação: a experiência do Instituto João Pinheiro 1909/1934. Bragança Paulista: USF, 2001. SCHUELER, Alessandra; RIZINI, Irma. MARQUES, Josué. Felismina e Libertina vão à escola: notas sobre a escolarização nas freguesias de Santa Rita e Santana (Rio de Janeiro, 1888-1906). Hist. Educ. (Online), v. 19,2015 , p. 145-165. Há também uma significativa produção sobre as demandas e fornecimento de escolas pela população imigrante, dentre os quais DEMARTINI, Zeila. Imigração e educação: discutindo algumas pistas de pesquisa. Pro-Posições (Unicamp), v. 15, n. 3, 2004, p. 215-228; KREUTZ, Lucio. Escolas comunitárias de imigrantes: histórias de coordenação e estruturas de apoio. Revista Brasileira de Educação, v. 31 n. 15, 2000, p. 156-179.
} 
ARRUDA, Rogério Pereira. Cidades-capitais imaginadas pela fotografia: La Plata (Argentina) e Belo Horizonte (Brasil), 1880-1897. Belo Horizonte: UFMG, 2011. 327f. Tese (doutorado em História). Universidade Federal de Minas Gerais.

AVILA, Mirian. O retrato na rua: memórias e modernidade na cidade planejada. Belo Horizonte: UFMG, 2008.

BARROS, José D. Assunção. Cidade e história. Petrópolis: Vozes, 2007.

BORSAGLI, Alessandro. O Vale do Córrego do Leitão em Belo Horizonte: contribuições da cartografia para compreensão de sua ocupação. SEMINÁRIO BRASILEIRO DE CARTOGRAFIA HISTÓRICA, 1, 2011. Anais ... Paraty: UFMG, 2011. Disponível em <https://www.ufmg.br/rededemuseus/crch/simposio/BORSAGLI ALESSANDRO.pdf>.

Acesso em 20 abr. 2016.

BOTELHO, Tarcisio. A migração para Belo Horizonte, 1897-1940. Cadernos de História, v. 9, Belo Horizonte: PUCMinas, 2007, p. 11-33.

BRESCIANNI, Maria Stela. Cidade e história. In: OLIVEIRA, Lucia Lippi (org.). Cidade: história e desafios. Rio de Janeiro: FGV, 2002, p.16-35.

BURGUIERE, Andre (org.). Dicionário das ciências históricas. Rio de Janeiro: Imago, 1993.

CARVALHO, José Murilo. Cidadania no Brasil: o longo caminho. Rio de Janeiro: Civilização Brasileira, 2008.

CORREA, Roberto Lobato. Estudos sobre a rede urbana. Rio de Janeiro: Bertrand Brasil, 2006.

COSTA, Geralda Nelma. Imprensa italiana em terra estrangeira: vozes sociais em ação (Belo Horizonte 1900-1920). Belo Horizonte: UFMG, 2005. 147f. Dissertação (mestrado em História). Universidade Federal de Minas Gerais.

DEMARTINI, Zeila. Infância e imigração: questões para a pesquisa. In: FREITAS, Marcus César (org.). Desigualdade social e diversidade cultural na infância e juventude. São Paulo: Cortez, 2006, p. 113-153.

DULCl, Otávio. Partidos e eleições em Belo Horizonte. In: DULCl, Otávio (org.). Belo Horizonte: poder, política e movimentos sociais. Belo Horizonte: C/Arte, 1996, p. 13-31.

DUTRA, Eliana Regina de Freitas. Caminhos operários nas Minas Gerais. São Paulo: Hucitec, 1988.

FARIA FILHO, Luciano Mendes; VEIGA, Cynthia Greive. Belo Horizonte e os processos educativos no movimento da cidade. Varia Historia, Belo Horizonte, n. 18, 1997, p. 203223.

FARIA FILHO, Luciano Mendes. Dos pardieiros aos palácios. Passo Fundo: UPF, 2001. FERRARO, Alceu. História inacabada do analfabetismo no Brasil. São Paulo: Cortez, 2009.

GOMES, Ângela Castro (org.). A nova velha república. Revista Tempo, v. 13 n. 26, 2009.

GOUGH, Phillipe Drumond. O contrapeso da ordem: o desenvolvimento espacial de Belo Horizonte (1897-1964). Belo Horizonte: UFMG, 1994. 289f. Dissertação (mestrado em Economia). Universidade Federal de Minas Gerais. 
GOUVEA, Maria Cristina; AFONSO, Bruna; BAHIENSE, Priscila; FIGUEIREDO, Elen Rose. O projeto republicano de instrução e as escolas isoladas urbanas: entre a transitoriedade e a permanência. Revista Brasileira de História da Educação, v. 16 n. 2, 2016, p. 311-340.

JACOB, Benjamin. Relatório apresentado ao Conselho Deliberativo pelo Prefeito Benjamin Jacob em 23 de setembro de 1907. Belo Horizonte: Imprensa Oficial do Estado de Minas Geraes, $1907 . \quad$ Disponível em <http://www.pbh.gov.br/arquivopublico/relatoriosdosprefeitos/1906-1907-BenjamimJacob.pdf>. Acesso em 20 abr. 2016.

KINGSTON, Ralph. Mind over matter? History and the spatial turn. Cultural \& social history, London: Berg, v. 7, n. 1, 2010, p. 111-122.

LE GOFF, Jacques. Por amor às cidades. São Paulo: Unesp, 1998.

LITTLE, Paul E. Territórios sociais e povos tradicionais no Brasil: por uma antropologia da territorialidade. Brasília: UNB, 2002.

MARINS, Paulo César. Habitação e vizinhança: limites da privacidade no surgimento das metrópoles brasileiras. In: SEVCENKO, Nicolai (org.). História da vida privada no Brasil República: da belle epoque a era do rádio. São Paulo: Companhia das letras, 1998, p. 131-214.

MINAS GERAIS. Regulamento da Instrucção Primaria e Normal do Estado de Minas. Belo Horizonte, MG: Imprensa Official do Estado de Minas Gerais, 1906.

MINAS GERAIS. Recenseamento de 1912. Belo Horizonte: Imprensa Official do Estado de Minas Gerais, 1912.

MINAS GERAES. Secretaria do Interior. Abaixo- assinado moradores Colônia Agrícola Afonso Pena. Relatórios de inspeção técnica. Arquivo Público Mineiro, SI 3358, 1912.

NASCIMENTO, Nilo; KRAJEWSKI, Jean-Luc; BRITTO, Ana Lucia. Águas urbanas e urbanismo na passagem do século 19 ao século XX. Revista UFMG, v. 20, n. 1, 2013, p. 102-133.

NICACIO, Karina; MYRHA, Paula. Demandas por ensino na cidade republicana: Belo Horizonte 1887-1924. CONGRESSO BRASILEIRO DE HISTÓRIA DA EDUCAÇÃO, 8 2015. Anais ... Maringá: Sociedade Brasileira de História da Educação, 2015.

PAULA, João Antonio; MONTE_MOR, Roberto. Processo histórico: três invenções da história de Belo Horizonte. Belo Horizonte: Cedeplar/UFMG, 2004.

PETERSON, Paul. Urban politics and changing schools. In: GOODESOW, Ronald; RAVITCH, Diane (ed.). School in the cities: consensus and conflits in american educational history. New York: Hobes \& Meier, 1983, p. 223-249.

RAMINELLI, Ronald. História urbana. In: CARDOSO, Ciro; VAINFAS, Ronaldo. Domínios da história. Rio de Janeiro: Campus, 1997.

RODRIGUES, Maysa. Sob o céu de outra pátria: imigrantes e educação em Juiz de Fora e Belo Horizonte, Minas Gerais (1888-1912). Belo Horizonte: UFMG, 2009. 346f. Tese (doutorado em Educação). Universidade Federal de Minas Gerais.

SACK, Robert. Human territoriality: its theory, and history. Cambridge: Cambridge University Press, 1986.

SANTOS, Milton. A natureza do espaço. São Paulo: Hucitec, 1996.

SENNET, Richard. Carne e pedra. Rio de Janeiro: Best Bolso, 2008. 
VAGO, Tarcísio Mauro. Cultura escolar, cultivo dos corpos: educação física e ginástica como práticas constitutivas dos corpos de crianças no ensino público primário de Belo Horizonte. Bragança: São Francisco, 2002.

VEIGA, Cynthia. Cidadania e educação na trama da cidade: a construção de Belo Horizonte em fins do século 19. Bragança Paulista: USF, 2002.

MARIA CRISTINA SOARES GOUVEA é professora na Faculdade de Educação da UFMG. É pesquisadora do Centro de Estudos e Pesquisas em História da Educação e do Núcleo de Estudos e Pesquisas em Infância e Educação Infantil.

Endereço: Rua Grão Pará 981/903 - 30150-341 - Belo Horizonte - MG - Brasil.

E-mail: crisoares43@gmail.com.

KARINA NICÁCIO é graduada em História pela UFMG, estudante do curso de Mestrado em Educação na UFMG, pesquisadora do Centro de Estudos e Pesquisas em História da Educação e bolsista de mestrado da Capes.

Endereço: Rua Dr. Archimedes Theodoro, 118 - 31652-230 - Belo Horizonte - MG Brasil.

E-mail: karinicacio2008@gmail.com.

Recebido em 20 de julho de 2016.

Aceito em 18 de novembro de 2016. 